\title{
The Calendar Impact And Trading Behavior: An Empirical Evidence From Around The Globe
}

Faleh Alrashidi, Public Authority for Applied Education and Training, Kuwait Manzoor Ahmed, Durham University, UK \& Lasbela University, Pakistan

Fahad Beneid, Public Authority for Applied Education and Training, Kuwait

\begin{abstract}
This paper is aimed to determine a change in the stock market's returns or its volatility from the globally selected Islamic mutual funds during the month of Ramadan, as all Muslims around the world eagerly and enthusiastically follow the rituals of the holy month of Ramadan. The paper uses monthly data of equity funds for those which are domiciled and those which operate globally within the period of January 2004 until December 2009. It is interesting to note that the empirical results provide no supporting evidence for the effect of the Ramadan month on the Islamic equity fund performance when examined using a dummy variable for the Ramadan month. Nevertheless, the evidence reveals that the volatility of stock returns remarkably decreases during this month. The reason for the decrease in volatility may be the result of the speed of economic activities during that month. Although, there is a decline in stock return volatility in the month of Ramadan, the return indicates no significant change.
\end{abstract}

Keywords: Trading Behavior; Ramadan Effect; Stock Returns; Volatility; Islamic Mutual Funds

\section{INTRODUCTION}

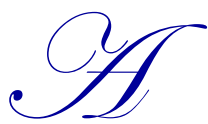

nomalies of any kind are the critical features of the financial market that stand in opposition to the efficient market hypothesis. Like other anomalies, researchers also underline those that are based on the Gregorian calendar which have potential impact on the performance of the financial market. Nonetheless, besides the Gregorian calendar, various other calendars are followed that are based on religious beliefs. For instance, the Jewish community follows the Hebrew calendar, which is stringently based on luni-solar; Christianity follows the Gregorian calendar, which is based on solar; the Hindu and Chinese people follow their own calendar; and the Muslim society follows the Islamic calendar, which is based on a lunar calendar as is referred as Hijri. In the Islamic calendar, Ramadan is a holy month during which the Muslim umma (community) is involved in many religious rituals, including the recitation of Holy Quran, fasting, and participation in social services. In addition, in the last decade of Ramadan, people sit in aaitakaf - a practice to get spiritual purity. So in order to admire and honour people's devotions to God, Muslim countries give relaxation during working hours. Therefore, Ramadan being the fasting - spiritually essential - month would virtually have an impact on the performance of the finances and other sectors of the economy, as Muslims tend to slow down under the pressure of fasting and hence allocate more time for their spiritual development. Therefore, this can be an empirical and systematic issue to investigate for the experts of Islamic finance, in general, and mutual funds, in particular, whether or not the month of Ramadan has an impact on the performance of stock returns, among other such anomalies of stock markets.

Currently, a great deal of change is observed in the trading activities of financial markets in Muslim countries all over the world. These changes include reduced banking and working hours and the greater tendency of market participants toward religious beliefs during the month of Ramadan. Most Muslim countries use both the Gregorian calendar, employed by businesses and governments, and the Islamic lunar calendar, which principally marks the religious activities and holidays. During Ramadan, the working hours of offices and business activities are 
drastically reduced. Since the reduced hours of work would naturally have an impact on the performance of work, these changes make it interesting to examine the behaviour of trading activity during Ramadan, as compared to the other months. Once the month of Ramadan comes to an end, there is a holiday called Eid-ul-Fitar which Muslims celebrate by buying new clothes and decorating their houses. Moreover, there is also a sharp increase in prices and costs of edible items and all the luxuries that are used for the Eid celebration during Ramadan. For example, prices of food and clothes, as well as some other commodities, rise. When the celebrations of Eid-ul-Fitr come to an end, the prices revert back to their normal status. Consequently, financial market trading activities are relatively affected by the behaviour of people during this month. It should be noted that since it is part of a lunar calendar, it moves slightly and each year it begins about 10 days earlier than the previous year.

The changes in this month are what make examination of the behaviour of trading activity so interesting. However, in spite of the major changes taking place in financial markets in virtually all Muslim countries, the available literature of Islamic finance does not provide a systematic study on this critical issue. In order to bridge this gap in the literature, this paper attempts to determine whether or not there is any significant difference in trading activity in Ramadan than in the other months. Hence, the paper explores and examines Ramadan effects on the globally selected Islamic mutual funds. In other words, there is a great opportunity to examine and determine any predictable patterns in the behaviour of stock returns and volatility that are present in the month of Ramadan but not in the other months of the year. It will provide interesting findings to both regulators and participants in the financial markets of Islamic countries in the Middle East, the Far East, and elsewhere (Mustafa, 2008).

This paper expects to determine a change in the stock market's returns or its volatility during the month of Ramadan, as all Muslims eagerly and enthusiastically follow the rituals of this holy month. There are considerably significant and visible changes in the social and economic lives of individuals during this time. Being considered as one of the five pillars of Islam, fasting during Ramadan is a mandatory duty for all adult Muslims who are physically capable; otherwise their exemption is permitted. In Ramadan, Muslims are required to abstain from eating food and drinking from dawn until sunset every day. Also, practising acts of piety and charity and praying are the other holy acts that are highly encouraged during this time. In addition to fasting, Ramadan is characterised by ritual prayers, recitations from the Holy Quran, and other acts of piety which significantly orientate the Muslim population toward Allah.

It should be noted that calendar anomalies have been the subject of considerable investigation, which are in opposition to the efficient market hypothesis. The Islamic calendar (also referred to as Hijri) is based on a lunar calendar and is followed in Muslim societies. The appearance of the new moon marks the start of this calendar which consists of twelve months. Comparing the duration of Islamic and Gregorian months, it becomes clear that the Islamic year is about eleven days shorter than the Gregorian year because, on average, a lunar month has only 29.53 days (Alrjoub, 2010). In the Islamic calendar, besides Ramadan, there are also other religious days and months that Muslim societies observe and celebrate, such as Eid-ul-Fitar and Eid-ul-Adha.

The principal aim of this paper is the empirical examination of Ramadan's effect on the globally selected Islamic mutual funds. It should be noted that the empirical analysis provided in this paper aims to contribute to the literature to fill a particular gap, as the existing body of knowledge mostly examines the Ramadan effect on the stocks or stock markets in a Muslim country. This study, however, aims to locate evidence, if any, for the effects of Ramadan on the performance of Islamic mutual funds operated globally rather than in a Muslim country.

The next section of this paper explains the review of literature, and is followed by sections describing data and econometric methodology, empirical findings and interpretation, and a conclusion.

\section{REVIEW OF RELATED LITERATURE}

Regarding the Islamic calendar effect, there have not been many significant studies, but some are available that explore the impact of Ramadan on stock returns. In an attempt to locate the impact of Ramadan, Hussain (1999) pointed out that this behaviour can make the stock market less volatile in volume and it also decreases stock returns in Pakistan. This phenomenon is not only observed in Pakistan's financial market; it also occurs in the Saudi Arabian stock market. As an example, reports by Seyyed et al. (2005) show a decline in volatility and trading 
activity, in terms of both volume and return, in the Saudi Arabian stock market during Ramadan. The investigation, carried out by Hussain (1999), of volatility in the stock market in Pakistan during Ramadan found it to be less than in other months, although it did not include the behaviour of average return before and after Ramadan.

In a study of the effects of Ramadan on the Karachi stock market, Khaled (2006) attempted to investigate the effects that the Islamic calendar may have on the Karachi stock market by using both conditional and unconditional analyses of risk. The Islamic calendar allows an easy study of variation in risks on both an annual and monthly basis. To accomplish this task, he used five models, starting with a simple one and ranging to a conditional risk model, with different models producing different results. He found a significant effect in this regard and observed that the average return in the month of Ramadan is smaller and insignificant. However, he reported that there is a positive and significant average return in the months of Shawwal and Zulqida, which is a sign of an afterRamadan effect in the Karachi stock market, considering the point that these two months come after Ramadan and the Eid-ul-Fitar festival. Since there is an increase in people's consumption during Ramadan and for the Eid festival, investment in the stock market decreases. To cite a reason for the growth of trading activity in the months of Shawwal and Zulqida in the Karachi stock market, he refers to the tendency of people to invest in the market after Ramadan and Eid. Furthermore, higher kurtosis and positive skewness found in the month of Shawwal demonstrate investors' preferences to invest during this month. To summarise, the literature supports an after-Ramadan effect in the Karachi stock market, which is rather low-risk during Ramadan.

The potential effect of Ramadan as a major moving calendar event and the significance of such effects on economic and financial variables are mentioned by some authors. Analysing various macroeconomic variables in Turkey, Alper, and Aruoba (2001) show occasional inefficiency of usual seasonal adjustment procedures based on fixed holidays to remove all seasonality when moving holidays, like Ramadan, are taken into account in the series. However, no significant effect of Ramadan on the Istanbul stock market was reported based on the findings of their study. It should be noted that they showed it is not possible for all deterministic seasonal components to be removed by conventional methods of deseasonalising moving events data. They demonstrate that in order to remove the residual seasonality, it is necessary that further deseasonalising be carried out by the application of specific categorical moving-event variables.

Moreover, during Ramadan, the volatility of the Pakistani stock market is significantly lower as found by Hussain (1999). He further mentioned that there are no significant changes in average returns during Ramadan, although the mean average return before and after Ramadan was not compared.

In another study, the effects of Ramadan on the Saudi Arabian stock market was examined by Seyyed et al. (2005), who conducted an analysis on several sector indices in the market. Their study revealed that there is a considerable decline in volatility and trading activity during the month of Ramadan. The latter study reconfirms Hussain's (1999) findings because both showed no significant change in average returns during Ramadan and did not examine the changes before and afterward.

In Jordan, possible distortions to the predictions of accepted models of asset pricing and some interesting findings on the behaviour of asset returns around a moving anomaly (the 'Ramadan Effect') were examined AlRjoub (2010). Using the Jordanian stock market return data, the study showed strong evidence in favour of the Ramadan effect during the study period. When accounting for the beginning and the end of the month, the results showed positive returns in the final 15 days of the month compared to an insignificant effect in the first 15 days. The study concluded that the month of Ramadan shows positive average returns. In addition, the first 15 days of the month are downers and returns in the rest of the month are gainers. The study therefore implied that the Ramadan effect is not a turn-of-the-month effect, since the latter confirms that daily stock returns are higher in the first half relative to the second half of the trading month.

Fazal's (1998) study shows that the volatility of stock returns significantly decreases during this month. The reason for the decrease in volatility may be the result of the speed of economic activities, which is generally slower. During Ramadan, trading hours in Pakistan reduce, which can be another reason for the decrease in volatility. It is also probable that many Muslims avoid speculating in the stock market during this month. The decline in volatility, caused either by moral factors or the decreased trading hours, needs more investigation and may 
provide useful clues in this area. It is worth mentioning that a significant change in average return does not happen in Ramadan. So, whilst it is a great opportunity for investors when volatility is reduced, the increase speculative trading will counterbalance this and result in the immediate disappearance of any benefits.

Possible explanations for such an occurrence might be simply the trading behaviour of institutional or individual investors during this month, or it could be a manifestation of the pre-holiday effect since the holiday is the three-day festival after Ramadan ends. However, this festival is part of the Muslims' religion where all feel satisfied after they approach God during the month of Ramadan. This could justify the higher pre-festival returns as a result of a positive sentiment. This result is in line with that of Chan et al. (1996) who consider the holiday effect within a cultural context for the stock exchanges of Malaysia, Singapore, India, and Thailand. They find a stronger holiday effect around cultural holidays compared to state holidays with no cultural origin.

For example, there is a study by Frieder and Subrahmanyam (2004) on the effect of religious holidays on the S\&P 500 index and New York Stock Exchange (NYSE) trading volumes. They focused on the Jewish High holy days of Rosh Hashanah and Yom Kippur and the Christian holy day of St Patrick. The results of the study showed a decline in volume on Rosh Hashanah and Yom Kippur and a price increase was observed during the two days before the start of Rosh Hashanah and St Patrick's Day.

However, the current studies covered the Ramadan effect on the stocks and stock market, which are focused only on selected single Muslim countries. Therefore, these studies failed to provide an effect on Islamic mutual funds which operate globally. In order to bridge this gap into the literature, this study will therefore examine the Ramadan effect on the Islamic mutual funds selected globally to find if there is any effect on the Islamic mutual funds.

\section{DATA AND EMPIRICAL METHODOLOGY}

The dataset utilised in this study consists of monthly net asset value (NAV) per unit prices of 52 Islamic equity funds. The data were sourced from Bloomberg at the National Investment Company (NIC) in Kuwait. This sample was selected from a larger sample, such that it only includes Islamic funds that mainly invest in equity. The sample for the Islamic equity funds represents nearly half of those currently in existence.

The paper examines monthly data of equity funds for those which are domiciled and those which operate globally within the period January 2004 to December 2009. The dataset holds information related to monthly net asset values (NAV), which has been calculated in order to test the comparative performance. Table 1 illustrates the descriptive statistics of the price weighted variable. The reported mean of the variable is 0.0044498 and the standard deviation is 0.0391548 . As shown in the table, the skewness value is -.5814787 which portrays that the return of the Islamic mutual funds is slightly skewed.

Table 1: Descriptive Statistics for the Islamic Mutual Funds

\begin{tabular}{|c|c|c|c|c|c|c|c|}
\hline Variable & Mean & Median & St. Dev. & Skewness & Kurtosis & Minimum & Maximum \\
\hline Price Weighted & 0.00444 & 0.0080 & 0.0391 & -1.58147 & -0.6232 & -0.16913 & 0.078742 \\
\hline
\end{tabular}

This paper analyses the effect of Ramadan while examining the Islamic mutual funds from all over the globe and controls for the effects of Ramadan, using specification formulated by Fazal (1998). The formulation used is:

Islamic mutual fund performance $=\alpha+\beta D_{t}$

$$
\text { ISfund }=\alpha+\beta\left(D_{t}\right)+u_{t}
$$

This is a univariate model with ISfund (Islamic mutual fund performance) is regressed on Dt. where $D_{t}$ is a dummy variable that is equal to 1 if it is Ramadan month; otherwise, it is zero. In this regression model (1), the intercept is the average returns for non-Ramadan months and 0 in other months. When an interactive dummy for each sub-period is used, the intercept represents average returns for non-Ramadan months for the specified subperiod and 0 otherwise. The slope on the dummy $\beta t$ accounts for the differences between average Ramadan returns 
and average returns in the remaining months. Therefore, if companies earn higher returns in the month of Ramadan, the slope $(\beta)$ should be significantly positive.

The following hypothesis is developed accordingly in order to test the main research question (hypothesis) of the paper; that is, whether or not the month of Ramadan has any impact (positive/negative) on Islamic mutual fund performance. The same research question is stated in the following testable hypothesis:

Hypothesis: There is no significant effect for the month of Ramadan on the Islamic mutual fund performance.

\section{EMPIRICAL FINDINGS AND INTERPRETATIONS}

Regression results for the Ramadan effects are presented in Tables 2 and 3 which examine the effects of the month of Ramadan as a dummy variable upon the performance of Islamic Equity Fund returns. The results in Table 2 indicate that the null hypothesis cannot be rejected; there is no significant effect for the Ramadan Month on the Islamic equity fund returns because the $p$-value is greater than the $10 \%$ level of significance (1-confidence level (90 $\%)$.

The standard Ordinary Least Squared econometric method is used to evaluate the Ramadan effect on Islamic mutual fund returns. As shown in Table 2, the t-value of -0.240 does not lie within the critical region with $10 \%$ level of significance. Thus, the dummy variable of Ramadan month effect appears irrelevant. Therefore, the study concludes that the Islamic mutual fund follows a similar trend in the month of Ramadan similar to other months.

While using two-period lag to examine the impact of Ramadan month, the study fails to reject the null hypothesis of an impact of Ramadan month on Islamic mutual funds' performance. As shown in Table 3, the $p$-value $(0.558)$ is large enough to reject the null hypothesis at $10 \%$ level of significance.

Table 2: Analysing the Ramadan Effect 1

\begin{tabular}{|c|c|c|c|c|}
\hline Method: Least Squares & \multicolumn{4}{|c|}{ Sample: 2004M01 2009M12 } \\
\hline \multicolumn{5}{|l|}{ Included observations: 72} \\
\hline \multicolumn{5}{|l|}{$\mathrm{ISLPW}=\mathrm{C}(1)+\mathrm{C}(2) * \mathrm{D} 1$} \\
\hline Variables & Coefficient & Std. Error & t-Statistic & Prob. \\
\hline $\mathrm{C}(1)$ & 0.004786 & 0.004852 & 0.986495 & 0.3273 \\
\hline $\mathrm{C}(2)$ & -0.00404 & 0.016808 & -0.240249 & 0.8108 \\
\hline R-squared & 0.000824 & \multicolumn{2}{|c|}{ Mean dependent var } & 0.00445 \\
\hline Adjusted R-squared & -0.01345 & \multicolumn{2}{|c|}{ S.D. dependent var } & 0.039155 \\
\hline S.E. of regression & 0.039417 & \multicolumn{2}{|c|}{ Akaike info criterion } & -3.60184 \\
\hline Sum squared resid. & 0.10876 & \multicolumn{2}{|c|}{ Schwarz criterion } & -3.5386 \\
\hline Log likelihood & 131.6663 & \multicolumn{2}{|c|}{ Durbin-Watson stat } & 1.29069 \\
\hline
\end{tabular}

According to these results, no supporting evidence is found for the effect of the Ramadan month on the Islamic equity fund performance when examined using a dummy variable for the Ramadan month (which takes the value of one for the respective two months of the year that contain the days of Ramadan). Thus, it is safe to conclude that the month of Ramadan does not have any impact on the performance of Islamic mutual fund returns.

Lastly, the existing literature focused only on a single country case in providing evidence for Ramadan effect. However, when this study examined Ramadan effect using global dataset failed to find any Ramadan effect. This may be due to the nature of those funds which operate globally, complying with the Shariah rules. This implies that while Ramadan effect might take place in Muslim countries, the global performance might set off the adverse effect of Ramadan. 
Table 2: Ramadan Effect

\begin{tabular}{|c|c|c|c|c|}
\hline Dependent Variable: ISLPW & \multicolumn{4}{|c|}{ Method: Least Squares } \\
\hline Sample: 2004M01 2009M12 & \multicolumn{4}{|c|}{ Included observations: 72} \\
\hline \multicolumn{5}{|l|}{$\mathrm{ISLPW}=\mathrm{C}(1)+\mathrm{C}(2) * \mathrm{D} 2$} \\
\hline Variable(s) & Coefficient & Std. Error & t-Statistic & Prob. \\
\hline $\mathrm{C}(1)$ & 0.003285 & 0.005036 & 0.65219 & 0.5164 \\
\hline $\mathrm{C}(2)$ & 0.007627 & 0.012885 & 0.591928 & 0.5558 \\
\hline R-squared & 0.00498 & \multicolumn{2}{|c|}{ Mean dependent var } & 0.00445 \\
\hline Adjusted R-squared & -0.00923 & \multicolumn{2}{|c|}{ S.D. dependent var } & 0.039155 \\
\hline S.E. of regression & 0.039335 & \multicolumn{2}{|c|}{ Akaike info criterion } & -3.60601 \\
\hline Sum squared resid & 0.108308 & \multicolumn{2}{|c|}{ Schwarz criterion } & -3.54277 \\
\hline Log likelihood & 131.8164 & \multicolumn{2}{|c|}{ Durbin-Watson stat } & 1.293324 \\
\hline
\end{tabular}

Nowadays in the financial market in Islamic countries, trading activities take place very regular. The current changes that occur include reduced banking and working hours and the greater tendency of market participants to adhere to religious beliefs during the fasting month of Ramadan. In the majority of Muslim countries, both the Gregorian and lunar calendars are followed - the Gregorian is used by businesses and governments and the Islamic lunar calendar principally marks the religious activities and holidays. Ramadan, being a part of a lunar calendar, moves slightly and each year (begins about 10 days earlier than the previous year). The month of Ramadan presents a great opportunity to examine and determine any predictable patterns in the behaviour of stock returns and volatility - something which is not presented by other months of the year. It provides interesting findings to both regulators and participants in the financial markets of Islamic countries in the Middle East, the Far East, and elsewhere.

A change in the stock market return or its volatility during the month of Ramadan is very likely since the Islamic countries around the world follow the ritual of this holy month. Considerably significant and visible changes occur in people's social and economic lives. Ramadan is one of the five pillars of Islam and it is obligatory for all adult Muslims to fast during this month, providing they are physically capable. It is worth noting that due to Ramadan, not a significant change takes place in the average return in the market. On the other hand, evidence reveals that the volatility of stock returns remarkably decreases during this month (Fazal, 1998). The reason for the decrease in volatility may be the result of the speed of economic activities, which are in general. In Fazal's (1998) study, it is shown that during Ramadan, trading hours in Pakistan reduce, which can be another reason for the decrease in volatility. It is because Muslims avoid speculating in the stock market during this month. The decline in volatility, caused either by moral factors or the decreased trading hours, requires more examinations that may give fruitful clues in this direction. It is important to note that a major change in average return does not happen in Ramadan. Thus, it is a great opportunity for investors when volatility is reduced. However, regarding this case, the increasing speculative trading results in the immediate disappearance of any benefits.

In the meantime, the findings of this paper contradict the results shown in studies of Khalid (2006) and Seyyed et al. (2004). Whereas there is after-Ramadan effect in the Karachi stock market (Khalid, 2006), a systematic pattern of decline in volatility during Ramadan was documented, implying a predictable variation in the market price of risk. This reveals that this anomaly appears to be consistent with a decline in trading activity during Ramadan (Seyyed et al., 2004). Albeit there is a decline in stock return volatility in the month of Ramadan, the return indicates no significant change.

\section{CONCLUSION}

This paper evaluates the impact of religious experience on financial markets and the possible distortions to the predictions of accepted models of asset pricing. The empirical findings of this paper underline some fascinating findings that are in contrast to the findings of the existing literature; that is, the findings of this paper show that no significant changes take place in the average return of the stock return during the month of Ramadan compared to other months of the year. This indicates that the month of Ramadan does not leave any sizeable impact on the trading behaviour of the financial market. Albeit during the month the Ramadan the financial market becomes less volatile, less volatility of the financial market is because overall trading activity declines. 


\section{AUTHOR INFORMATION}

Dr. Faleh Alrashidi, Assistant Professor, Public Authority for Applied Education and Training, College of Business Studies, Kuwait. E-mail: fxa38@ case.edu (Corresponding author)

Dr. Manzoor Ahmed, Visiting Academic Scholar, Durham Business School, Durham University, UK and Assistant Professor of Economics and acting Dean, Faculty of Social Sciences, Management and Information Technology, Lasbela University, Balochistan, Pakistan. E-mail: economist.luawms@gmail.com

Fahad Beneid, Assistant Professor at Banking and Insurance Department, College of Business Studies, Public Authority for Applied Education and Training, Kuwait. E-mail: fbeneid@ hotmail.com

\section{REFERENCES}

1. Al Rjoub, Samer A. M. (2010). A moving anomaly: The Ramadan effect in the case of Jordan. Review of Islamic Economics, 14(2), 189-198.

2. Alper, C. E., \& Arouba, S. B. (2001). Deseasonalizing macroeconomic date: A caveat to applied researchers in Turkey. ISE Review, 5(18), 33-52.

3. Chan, K. C., Khanthavit, A., \& Thomas, H. (1996). Seasonality and cultural influences on four Asian stock markets. Asia Pacific Journal of Management, 13, 1-24.

4. Fazal, H. (1998). A seasonality in the Pakistani equity market: The Ramadhan effect. (MPRA Paper 5032). University Library of Munich, Germany.

5. Frieder, L., \& Subramanyam, A. (2004). Nonsecular regularities in returns and volume. Financial Analysts Journal, 60, 29-34.

6. $\quad$ Hussain, J. (1999). Islamic law and society. Sydney: The Federation Press.

7. Khalid, A. M. (2006). Bond market developments in emerging markets: Prospects and challenges for Pakistan. Research Bulletin, State bank of Pakistan, 1, 43-62.

8. Mustafa, K. (2008). The Islamic calendar effect on Karachi stock market. Paper presented at the 8th International Business Research Conference on March 27-28, 2008 Dubai, UAE.

9. Seyyed, F. J., Abraham, A., \& Al-Hajji, M. A. (2004). Seasonality in stock returns and volatility: The Ramadan effect. Research in International Business Finance, 19(3), 374-383. 
NOTES 